\title{
Estimulación multisensorial en el desarrollo integral infantil: Revisión sistemática desde la perspectiva de distanciamiento social
}

\section{Multisensory stimulation in comprehensive child development: systematic review from the perspective of social distancing}

1 Silvia Beatriz Acosta Bones

https://orcid.org/0000-0002-4612-7432 Universidad Técnica de Ambato, Facultad de Ciencias de la Educación, Carrera de Educación Inicial. Ambato, Ecuador.

silviabacostab@uta.edu.ec

2 Elena del Rocío Rosero Morales

https://orcid.org/0000-0001-7004-3207

Universidad Técnica de Ambato, Facultad de Ciencias Humanas y de la Educación, Carrera de Educación Inicial. Ambato, Ecuador.

elenadroserom@uta.edu.ec

3 Jeanneth Caroline Galarza Galarza (iD) https://orcid.org/0000-0002-2837-5651 Universidad Técnica de Ambato, Facultad de Ciencias Humanas y de la Educación, Carrera de Educación Inicial-Educación Básica. Ambato, Ecuador, Doctorando en Ciencias de la Educación-Universidad Nacional de Trujillo, Perú. jeannethcgalarzag@uta.edu.ec

4 Milena Aracely Estupiñán Guamaní (iD) https://orcid.org/0000-0002-5874-576. Universidad Técnica de Ambato, Facultad de Ciencias Humanas y de la Educación, Carrera de Educación Inicial. Ambato, Ecuador ma.estupinan@uta.edu.ec

Artículo de Investigación Científica y Tecnológica Enviado: 24/12/2021

Revisado: $29 / 12 / 2021$

Aceptado: $12 / 01 / 2022$

Publicado:08/03/2023

DOI: https://doi.org/10.33262/concienciadigital.v6i1.4.1991

Cítese:

Acosta Bones, S. B., Rosero Morales, E. del R., Galarza Galarza, J. C., \& Estupiñán Guamaní , M. A. (2023). Estimulación multisensorial en el desarrollo integral infantil: Revisión sistemática desde la perspectiva de distanciamiento social. ConcienciaDigital, 6(1.4), 141-162. https://doi.org/10.33262/concienciadigital.v6i1.4.1991

CONCIENCIA DIGITAL, es una Revista Multidisciplinar, Trimestral, que se publicará en soporte electrónico tiene como misión contribuir a la formación de profesionales competentes con visión humanística y crítica que sean capaces de exponer sus resultados investigativos y científicos en la misma medida que se promueva mediante su intervención cambios positivos en la sociedad. https://concienciadigital.org .

La revista es editada por la Editorial Ciencia Digital (Editorial de prestigio registrada en la Cámara Ecuatoriana de Libro con No de Afiliación 663) www.celibro.org.ec 


\section{Palabras}

claves:

estimulación

multisensorial, desarrollo

infantil áreas de desarrollo, distanciamiento social.

\section{Resumen}

Introducción: En el contexto educativo uno de los objetivos principales es trabajar el desarrollo integral infantil, el currículo de Educación Inicial caracteriza los ámbitos de desarrollo y aprendizaje para infantes y describen objetivos y destrezas que debe desarrollarse. Es así como la estimulación sensorial es muy importante en el desarrollo de las áreas cognitiva, afectivo social, motor y del lenguaje las cuales han sido afectadas por el distanciamiento social. Objetivo: Sintetizar los estudios realizados sobre la estimulación sensorial en el desarrollo infantil durante el distanciamiento social. Metodología. El estudio siguió una metodología descriptiva, el empleo de métodos teóricos y empíricos y la RSL (Revisión Sistemática de Literatura), permitió consultar en proyectos de titulación vinculados al proyecto de investigación de la Carrera "Estimulación multisensorial temprana basada en la metodología Montessori para niños/as de 0-5 años con o $\sin$ necesidades educativas especiales post distanciamiento social" realizados por las estudiantes de Educación Parvularia y Educación Inicial de los periodos que corresponden al distanciamiento social. Resultados: la selección de 7 investigaciones que contribuyeron a sintetizar los fundamentos teóricos sobre la estimulación sensorial en el desarrollo integral infantil, facilitando la concreción de la estimulación en 7 sentidos que potencian el desarrollo integral del niño como son: 1. La estimulación visual. 2. La estimulación auditiva. 3. La estimulación táctil. 4. La estimulación gustativa. 5. La estimulación olfativa 6. La estimulación vestibular 7. La estimulación propioceptiva que permite ejecutar las funciones básicas del niño como: comprensión, atención, memoria, lenguaje, sensopercepciones, esquema corporal, lateralidad, direccionalidad, nociones temporales, motricidad fina y gruesa en el área cognitiva, afectivo social, motor y lenguaje muy necesarios en la infancia y un desafío permanente que en tiempo de distanciamiento social se ha visto limitado. Conclusiones: La sistematización de las investigaciones relacionadas a la estimulación multisensorial en el desarrollo infantil resaltan la necesidad de que el niño tenga una adecuada estimulación del entorno para que logre potenciar su desarrollo integral el cual se ha visto limitado por el distanciamiento social. 


\section{Keywords:}

multisensory

stimulation,

child

development, developmental areas, social distancing.

\section{Abstract}

Introduction: In the educational context, one of the main objectives is to work on children's integral development; the Early Education curriculum characterizes the areas of development and learning for infants and describes the objectives and skills to be developed. Thus, sensory stimulation is significant in the development of the cognitive, affective-social, motor, and language areas affected by social distancing. Objective: To synthesize the studies on sensory stimulation in child development during social distancing. Methodology. The study followed a descriptive methodology; the use of theoretical and empirical methods and the SLR (Systematic Literature Review) allowed consulting in degree projects linked to the research project of the Program "Early multisensory stimulation based on the Montessori methodology for children from 0-5 years old with or without special educational needs after social distancing" carried out by the students of Nursery Education and Early Childhood Education of the periods that correspond to social distancing. Results: the selection of 6 investigations that contributed to synthesizing the theoretical foundations on the sensorial stimulation in integral child development, facilitating the concretion of the stimulation in 7 senses that promote the child's integral development, such as 2 . Auditory stimulation. Tactile stimulation. 4. Taste stimulation. Olfactory stimulation 6 . The vestibular stimulation 7. The proprioceptive stimulation allows executing the essential functions of the child such as comprehension, attention, memory, language, sensoperceptions, body scheme, laterality, directionality, temporal notions, fine and gross motor skills in the cognitive area, social, affective, motor, and language vital in childhood and a permanent challenge that in time of social distancing has been limited. Conclusions: The systematization of previous research on multisensory stimulation in child development highlights the need for the child to have an adequate stimulation of the environment to enhance his or her integral development, which has been limited by social distancing. 


\section{Introducción}

Según Alirio (2016), la sociedad requiere de cambios independientemente del paradigma político, económico o social, el cual limita a la educación como principal fuente de conocimiento y aprendizaje en el infante, a esto se suma las exigencias del mundo moderno y una de las prioridades de los gobiernos actuales con el distanciamiento social debe ser la primera infancia como grupo vulnerable.

Las etapas tempranas de vida constituyen un período crítico o sensible. En este período, las experiencias que se establecen con el entorno influirán no sólo en la forma de construir la identidad, sino también en cómo se estructure y funcione el cerebro, sentándose las bases del aprendizaje y la socialización (Rosenzweig \& Leiman, 1992).

El desarrollo es concebido como ciertos cambios que ocurren en los seres humanos, desde la concepción hasta la muerte, y se dan en forma ordenada y permanente por un período razonable de tiempo. Estos cambios, cuando ocurren en el principio de la vida, son el resultado de conductas más adaptativas, organizadas, efectivas y complejas (Woolfolk, 1986).

Entonces el desarrollo depende de la calidad de las condiciones sociales, económicas y culturales en las que nacen, crecen y viven los niños, y que son influenciados por la calidad de los estímulos del entorno en el que se encuentran y de las oportunidades que el entorno les ofrece.

Es así como el desarrollo infantil es un proceso de cambios continuos y secuenciados que comienza desde la concepción y persiste a lo largo de la vida, en la que se producen cambios progresivos que garantizan el crecimiento, la maduración y la adquisición de las funciones humanas como el habla, la escritura, el pensamiento, los afectos, la creatividad entre otros.

Según el currículo el desarrollo infantil es integral y contempla todos los aspectos cognitivos, sociales, psicomotrices, físicos y afectivos, interrelacionados entre sí y que se producen en el entorno natural y cultural estimulando la exploración en ambientes ricos y diversos, con calidez, afecto e interacciones positivas para garantizar y promover oportunidades de aprendizaje. Las bases teóricas del diseño curricular consideran la necesidad de crear ambientes estimulantes y positivos, donde los niños puedan acceder a experiencias de aprendizaje efectivas desde sus primeros años, con el fin de fortalecer el desarrollo infantil en todos sus ámbitos, lo cual incidirá a lo largo de su vida. Propone la formación integral de los niños, esto implica el desarrollo de los diferentes ámbitos que permiten especificar la tridimensionalidad de la formación del ser humano, es decir, lo actitudinal, lo cognitivo y lo psicomotriz (MINEDUC, 2014).

Los estímulos son todos aquellos impactos sobre el ser humano que producen en él una 
reacción, es decir, una influencia sobre alguna función. Los estímulos son entonces de toda índole, tanto externos como internos, físicos y/o afectivos.

Asimismo, garantizar experiencias positivas durante los primeros años de vida como un ambiente familiar social estimulante y lleno de afecto, una educación inicial de calidad, entorno lúdico, y adecuado cuidado de salud y nutrición pueden potenciar todos los ámbitos del desarrollo infantil y tener incidencia a lo largo de la vida del sujeto (Tinajero \& Mustard, 2011).

Albornoz y Guzmán (2016), manifiestan que los entornos multisensoriales potencian el desarrollo integral durante los tres primeros años y desarrollan en un $90 \%$ el cerebro permitiendo que los aprendizajes sean más rápidos y efectivos. Desde el nacimiento el niño recibe estimulación del entorno y de éste depende la efectividad y desarrollo integral en el área cognitivo, afectivo social, motriz y de lenguaje.

Es así como María Montessori considera que la estimulación en edades tempranas desarrolla las capacidades de percibir, descubrir y razonar de forma independiente construyendo sus propios aprendizajes, y potencia el desarrollo de la autonomía e independencia la cual le ayudará a adaptarse a su entorno.

El Sistema nervioso central es estimulado por medio de los sentidos de tal manera que, si se presenta un limitado rendimiento en uno o varios de ellos, la estimulación multisensorial fortalece y mejora las habilidades con el entorno para lograr su independencia. Las áreas conductuales que se deben estimular son especialmente la que busca la autoafirmación, la cooperación y la competencia cognitiva, lingüística y social.

Según Warnok (2014), la estimulación nos permite ofrecer una serie de estímulos aislados, puesto que las sensaciones son alimento para el cerebro, pero si los procesos sensoriales no están bien organizados, no pueden ser digeridos ni nutrir al cerebro.

Algunos autores consideran que el espacio sensorial es un área física diseñada para

estimular el sistema nervioso central, utilizando para ello una variedad de materiales y herramientas que incluyen además apoyos psicológicos para las familias y orientación para el maestro. Estos mismos autores, indican que, si los niños presentan cierta falta de rendimiento en el sistema propioceptivo, la estimulación de los estados multisensoriales le ofrece la posibilidad de fortalecer uno de sus sentidos que está en buen estado de funcionamiento e ir adquiriendo conocimientos a través de un aprendizaje normal, sencillo y seguro para mejorar las habilidades comunicativas y la interacción con el entorno hasta lograr la integración e independencia (Molina, 2008).

Desde la propia metodología Montessori se ha podido sistematizar y comprobar que mientras mayores sean los estímulos multisensoriales que reciben los niños en las 
primeras edades, mejor será su desempeño y desarrollo integral. Estimular sus sensaciones y percepciones permite que vaya descubriendo el mundo que le rodea encontrando significado a lo que se le enseña, descubre y aprende, para así ir formando sus propios conceptos, juicios y valoraciones (Carbajo, 2014).

El proceso de enseñanza aprendizaje está caracterizado por la actividad y la educación de los sentidos. Esto quiere decir que el niño aprende a través de las actividades que proponemos y la estimulación que potencian sus sentidos (Rousseau, 2012).

El estimular los sentidos de los peques puede resultar bastante sencillo con un poco de imaginación. Jugar con agua, caminar descalzos sobre la grama, probar distintos sabores u olores, amasar distintos materiales como granos, harina o plastilina, escuchar sonidos de animales o diferentes melodías y ritmos, golpear un par de ollas o masajear su cuerpo nombrando cada parte de él. Todas son actividades que podemos hacer con los pequeños y que le ayudarán a abrir esas ventanas de la percepción humana, tan importantes durante toda nuestra vida.

Para Salvador (1989), la estimulación precoz parte en esencia del hecho, científicamente demostrado, de que para que se produzca un normal desarrollo físico e intelectual es necesario estimular adecuadamente el organismo durante su período de crecimiento. El objetivo principal es la potenciación máxima de las posibilidades físicas e intelectuales del niño mediante la estimulación regulada y continuada llevada a cabo en todas las áreas sensoriales, pero sin forzar en ningún sentido el curso lógico de la maduración del sistema nervioso central.

Según Tamayo (2000), quien afirma que la estimulación temprana considera múltiples acciones que favorecen al desarrollo del ser humano en sus primeros años, entre los que tenemos principalmente la provisión de diferentes estímulos que impresionan a los diversos receptores. Una significativa área de la estimulación está en el hecho de trabajar alrededor de los sentidos de la visión, audición y tacto. Si bien es cierto que estos receptores son importantísimos en el desarrollo integral, tampoco deja de serlo la estimulación propioceptiva.

En este estudio se tomaron trabajos relacionados a la estimulación, visual, auditiva, táctil, gustativa, olfativa, vestibular y propioceptiva considerando que el niño aprende del medio a través de sus sentidos los cuales permite su adaptación al entorno y al desarrollo de las principales capacidades básicas.

\section{Estimulación visual}

Según Téllez (2003), La estimulación temprana favorece la psicomotricidad e impulsa el proceso del conocimiento visual y auditivo. 
Algunas estimaciones sugieren que entre el 80 y el $90 \%$ de la información que recibimos del mundo exterior es visual (Briones, 1994).

Desde este fundamento la vista es un sentido muy importante pues permite percibir el mundo exterior y transmitir conocimientos que los recibimos del entorno.

La estimulación visual en el recién nacido ayudará a potenciar el reflejo de acomodación (enfoque) para que comience a discriminar otros colores, así como también a seguir movimientos para que desarrolle una visión de profundidad con la ayuda de objetos brillantes que le llama la atención. A medida que va creciendo irá calculando la distancia a la que se encuentran las imágenes y desarrollando ciertas destrezas perceptivas que le permitirá comprender su mundo espacial, como la memoria y discriminación visual.

\section{Estimulación auditiva}

Según Martenot (1993), "el oído es el centro vital del hombre, el centro de su equilibrio psicofisiológico". Una buena estimulación auditiva favorece a la comprensión de los diversos sonidos de la naturaleza y del medio que le rodea los cuales permiten el desarrollo de nuevos aprendizajes.

El estudio de la audición se enmarca en el ámbito más extenso del estudio de la percepción, que se puede concebir, en sentido más amplio, como la actividad cognitiva inducida por la presentación física del objeto, a través de los sentidos (García-Albea, 1999).

Por consiguiente, a través de un apropiado desarrollo de la percepción y discriminación auditiva, se favorece el adecuado procesamiento lingüístico formal y otras manifestaciones verbales más generales como: la atención, la escucha, los tiempos de espera, la empatía, la percepción del silencio, y la capacidad estética entre otros. Estos requisitos son fundamentales para el acceso a la lectura y la escritura (Herrera, 2001).

Según recientes estudios en la neurociencia cognitiva, la estimulación auditiva es necesaria en los primeros seis años para el desarrollo intelectual y cognitivo y para el desarrollo integral del niño. Durante esta etapa se generan suficientes conexiones neuronales que serán la base del desarrollo de nuevos aprendizajes y habilidades futuras, si al niño se le brinda esta estimulación adecuada, tendrá un florecimiento neuronal que fomentará la creación de nuevas sinapsis, lo cual puede producir éxitos escolares (Botella, 2016).

A lo largo de la vía auditiva intervienen algunas habilidades que van desde el procesamiento de la información auditiva hasta llegar a la interpretación de esta en el cerebro (Martínez, 2015). 
Estas habilidades según Cañete (2006) son: discriminación auditiva, localización auditiva, atención auditiva, aspectos temporales, asociación auditiva, desempeño auditivo, memoria auditiva.

Estas habilidades ayudan a discriminar y diferenciar sonidos para prestar atención a señales auditivas verbales y no verbales y también aspectos temporales para detectar los distintos aspectos temporales en una señal acústica e identificar un sonido con la fuente o situación que lo produce, habilidad para comprender la totalidad de una palabra, almacenar, recordar y reconocer el orden de presentación de estímulos auditivos verbales y no verbales (Cañete, 2006).

La consecuencia de esta mala audición da lugar a problemas de escucha y de concentración, siendo esenciales para el proceso de los aprendizajes cognitivos, de lenguaje y conductas sociales (Peiró, 2017).

\section{Estimulación táctil}

El sentido táctil permite el ingreso de la información, al igual que el oído y la vista. En la sala de estimulación se trabaja con texturas que le permitirá al niño tener sensibilidad táctil.

Según Baber (2005), la mejor estimulación es el contacto de los padres. Acariciar y recorrer suavemente la cara del niño, besarlo y reír con él como si fuera un juego, pero de forma muy relajada. Coger un cochecito o juguete con ruedas agradables al tacto y recorrerle el cuerpo con él. Coger diferentes texturas de tela, papel, trozos de bolsas de plástico, peluches, objetos ásperos y suaves, etc. y dejar que el niño las explore con las manos o pasárselas por el cuerpo para que experimente las diferentes sensaciones y contrastes.

Los estímulos táctiles aumentan movimientos de la motricidad necesarios para el desarrollo de la locomoción y en el proceso de gateo para posteriormente ayudar en los primeros pasos que dará el niño para lograr el equilibrio y coordinación de los movimientos corporales.

\section{Estimulación gustativa}

La estimulación sensorial es la apertura de los sentidos, que nos comunica la sensación de estar más vivos. Los colores son más intensos, y los olores más sutiles y los alimentos tienen otro sabor y una textura más definida. La vida en general toma otro significado, porque los sentidos pasan a un primer plano, favoreciendo el vivir más intensamente. Una estimulación sensorial provoca un estado de receptividad sensitiva que repercute en una mayor atención, la que a su vez es como la mecha que enciende la consciencia (Gómez, 2010). 
Este sentido permite la discriminación de sabores, es necesario estimular y ampliar las experiencias al utilizar diferentes sabores los cuales puedan distinguir, no solo preferencia sino también favorecer la deglución y masticación.

\section{Estimulación olfativa}

Por medio del olfato el bebé reconoce a su madre y busca la succión para alimentarse como primer contacto. Estudios realizados demuestran que la memoria olfativa está asociada con experiencias altamente emocionales, de hecho, también los olores pueden precipitar memorias traumáticas (Vermetten \& Bremner, 2003).

Así, el estudio de la asociación entre los olores y la conducta emocional ha sido útil para proporcionar información sobre la conducta y los mecanismos cerebrales relacionados en la modulación de la emoción, como el miedo (Takahashi, 2005).

En efecto, los olores de predadores como el olor de gato son efectivos para producir miedo condicionado en roedores (Blanchard et al., 2001), con la participación de la amígdala baso lateral (Takahashi, 2005).

Para estimular el área olfativa se puede emplear diferentes tipos de aromas que los distinguiendo los olores fuertes y suaves, agradables y desagradables.

\section{Estimulación vestibular}

El sistema vestibular tiene una participación en la dinámica postural y equilibradora se produce, principalmente, a través de tres reflejos: el reflejo vestíbulo-ocular, el reflejo vestíbulo-espinal y el reflejo opto cinético (Lázaro, 2008).

El equilibrio inicia con el desarrollo de las conductas motrices que son los cimientos del aprendizaje humano. El trabajo del equilibrio pertenece a lo que se conoce como las conductas motrices: la equilibración general, la coordinación dinámica general y la coordinación viso motriz de base las cuales ayudan con el tono y la postura; los desplazamientos y saltos y con las distintas praxias que ponen en relación el ojo y cualquier parte del cuerpo y constituyen los cimientos del aprendizaje humano.

El proceso de integración sensorial se desarrollan tres sensaciones básicas: táctil, propioceptiva y vestibular. En el segundo escalón, estas sensaciones básicas se integran con la percepción corporal, la coordinación de ambos lados del cuerpo, la planificación motora, la duración de la atención, el nivel de actividad y la estabilidad emocional. En el tercer nivel de la integración sensorial, las sensaciones auditivas y visuales entran en el proceso (Ayres, 1983).

Ninguna de las funciones se desarrolla sólo a una edad. El cerebro del niño procesa cada nivel de la integración sensorial durante toda la infancia. El niño aprende las mismas 
cosas una y otra vez, primero gateando, después andando y más tarde montando en bicicleta (Ayres, 1983).

\section{Estimulación propioceptiva}

La estimulación de los propioceptores, excitan las terminaciones que ponen en movimiento circuitos aferentes, los cuales tras pasar por la médula ponen en movimiento neuronas motoras, que siguiendo un circuito eferente facilitan de manera refleja o automática, contracciones musculares. Existen 3 categorías de receptores propioceptivos: musculares, articulares y vestibulares (Gutiérrez \& Ruiz, 2018).

La estimulación del sistema propioceptivo ayudará a la coordinación de los movimientos, explorar diferentes formas de desplazamientos, desarrollando su capacidad motora gruesa y alcanzando niveles crecientes de coordinación corporal, mantener el equilibrio en los movimientos gruesos del cuerpo adoptando un adecuado control postural que le permita disfrutar de la realización de nuevas formas de movimientos, Desarrollar la coordinación viso motriz de ojo-mano y pie a través de la manipulación de objetos, Explorar su cuerpo a través de los sentidos, movimientos y posiciones para una adecuada estructuración del esquema corporal (MINEDUC, 2014).

Según el currículo de educación inicial las destrezas que se desarrollan en cada una de las edades permiten un desarrollo integral del niño en las áreas cognitivas, motrices, afectivo social y de lenguaje.

Área cognitiva: Permite al niño comprender y adaptarse a nuevas situaciones donde tiene que pensar e interactuar con su entorno. Esta área se enriquece al experimentar nuevas vivencias donde el niño intente hallar las soluciones en poco tiempo (Chiquillo, 2015).

Área Motriz: Se refiere a la habilidad de moverse y desplazarse que adquiere el niño progresivamente, es decir realizar actividades de motricidad fina y motricidad gruesa. Además, esta área permite al infante que pueda explorar su entorno y crear conciencia sobre lo que observa y manipula para establecer así nuevos conceptos (Chiquillo, 2015).

Área Socio-Afectiva: Se refiere a las experiencias sociales y afectivas del niño para que se integre a un grupo de personas sin ningún problema, lo cual ayuda en la formación y estructuración de autonomía y auto concepto para favorecer su óptimo desarrollo y convivencia (Chiquillo, 2015).

Área de Lenguaje: Aquella que está referida a las habilidades que le permiten al niño comunicarse con su entorno y considera tres aspectos: la capacidad comprensiva, expresiva y gestual (Chiquillo, 2015).

La estimulación sensorial potencia destrezas para la iniciación a la pre escritura, pues se 
argumenta que el desarrollo grafo motriz en el nivel inicial es muy importante debido a que el niño y la niña necesitan un óptimo desarrollo de la motricidad fina para la realización de una buena grafía, para lo cual la estructura céfalo-caudal y próximo distal juegan un rol fundamental, permitiendo adquirir habilidades y destrezas adecuadas, mismas que ayudan a organizar y secuenciar actividades las cuales dan paso a la pre escritura.

\section{Metodología}

La investigación siguió una metodología descriptiva, métodos teóricos, analíticosintético, inductivo-deductivo y revisión documental; que permitió realizar una RSL (Revisión Sistemática de Literatura).

Criterios de inclusión

1. Tipo de estudios: Estudios de revisiones teóricas sobre estimulación multisensorial y desarrollo integral infantil durante el distanciamiento social en proyectos de integración curricular de la Universidad Técnica de Ambato Carrera de Educción Inicial vinculados al proyecto de investigación con el tema: "Estimulación multisensorial temprana online basada en la metodología Montessori para niños/as de 0-5 años con o sin necesidades educativas especiales post distanciamiento social"

2. Tipo de participantes: niños de educación inicial en las edades comprendidas entre 0 a 5 años.

3. Tesis de maestrías vinculadas al proyecto de investigación de la Carrera.

Criterios de exclusión

4. Estudios o investigaciones realizadas antes del periodo de distanciamiento social.

La tabla 1, muestra un resumen de los resultados del análisis realizado en cuanto a los proyectos vinculados para la presente investigación. 


\section{Tabla 1}

\section{Resultado de proyectos vinculados para la investigación}

\begin{tabular}{lll}
\hline \multicolumn{1}{c}{ Autorías, Titulo y año } & Base de Datos & \multicolumn{1}{c}{ Intervención } \\
\hline Tinoco, M. (2021). & & Se realiza un análisis en la \\
Interpretación de imágenes & & interpretación de imágenes y el \\
en la iniciación a la lectura & Repositorio & desarrollo de habilidades en la \\
en el nivel inicial. & UTA & discriminación visual para iniciar \\
& & la lectura en el nivel inicial.
\end{tabular}

Resaltan la importancia
de la estimulación
visual para la
interpretación de
imágenes en el
desarrollo integral del
niño

Moposita, E. (2021).

Repositorio

Mediante una búsqueda

y análisis de información, en

Lineamientos didácticos para UTA

la aplicación de ejercicios

grafos motores en

el nivel inicial. libros, artículos científicos,

repositorios se fundamentó los

lineamientos didácticos

adecuados para la aplicación de

ejercicios grafo motores

utilizando la estimulación

sensorial para el desarrollo de las destrezas de motricidad fina.

Es necesario tener un

Fundamento teórico

sobre los lineamientos

didácticos para

desarrollar la

coordinación viso

manual y lograr un

óptimo desarrollo grafo

motriz y esto depende

mucho de los estímulos

que reciba del contexto.

Se propone una guía de

Núñez, M. (2021). La

Estimulación sensorial en el proceso de lectoescritura en los niños del nivel Inicial 11 de la Escuela de Educación Básica Jerusalén.

Repo

Repositorio UTA Analiza la incidencia de la
estimulación sensorial en el proceso de lectoescritura en los niños del nivel inicial II. actividades que potenciará el proceso lectoescritor y el desarrollo integral del niño.

La estimulación sensorial beneficia el desarrollo de habilidades y destrezas para futuros aprendizajes.

\begin{tabular}{lll}
\hline Culqui, Y. (2021). Repositorio UTA Se realiza un análisis de la & La estimulación sensorial es \\
Estimulación sensorial en el & estimulación sensorial en el & esencial para el desarrollo de \\
desarrollo de las destrezas & desarrollo de las destrezas del área & las destrezas, aquí se propone \\
del área & socio afectiva en niños de 2 a 3 & una guía que permitirá a \\
socio afectiva en niños de & años que plantea el currículo de & padres de familia y docentes \\
2 -3 años del cantón & educación inicial. & aplicar técnicas para lograr el \\
Ambato en tiempo de & & desarrollo de las destrezas del \\
pandemia. & & área socio afectiva y su \\
& & adaptación al entorno.
\end{tabular}




\section{Tabla 1}

Resultado de proyectos vinculados para la investigación (continuación)

\begin{tabular}{|c|c|c|c|}
\hline Autorías, Titulo y año & Base de Datos & Intervención & Conclusiones \\
\hline $\begin{array}{l}\text { Guerrero, M. (2021). } \\
\text { La metodología } \\
\text { Montessori aplicada en el } \\
\text { hogar para el desarrollo de } \\
\text { aprendizajes significativos } \\
\text { de los } \\
\text { niños/as del nivel inicial II }\end{array}$ & $\begin{array}{l}\text { Repositorio } \\
\text { UTA }\end{array}$ & $\begin{array}{l}\text { Analiza el método Montessori } \\
\text { aplicado en el hogar para } \\
\text { desarrollar e ir fortaleciendo } \\
\text { aprendizajes significativos en el } \\
\text { cual se ponen en juego la } \\
\text { estimulación de los sentidos que le } \\
\text { permitan adaptarse al entorno y } \\
\text { conseguir la autonomía e } \\
\text { independencia. }\end{array}$ & $\begin{array}{l}\text { La metodología Montessori } \\
\text { busca la autonomía y la } \\
\text { libertad del niño para realizar } \\
\text { las actividades que le sean } \\
\text { útiles y lograr aprendizajes } \\
\text { significativos, gracias a los } \\
\text { estímulos del entorno que } \\
\text { son percibidos por los } \\
\text { sentidos. }\end{array}$ \\
\hline $\begin{array}{l}\text { Betty, T. (2021). } \\
\text { La educación física online } \\
\text { basada en la metodología } \\
\text { Montessori en niños/as de } \\
\text { educación inicial II } \\
\text { (de } 3 \\
\text { - } 5 \text { años)" }\end{array}$ & $\begin{array}{l}\text { Repositorio } \\
\text { UTA }\end{array}$ & $\begin{array}{l}\text { Analiza la Educación Física online } \\
\text { basada en la metodología } \\
\text { Montessori trabajada con niños/as } \\
\text { de 3-5 años, argumentando } \\
\text { teóricamente las variables. }\end{array}$ & $\begin{array}{l}\text { La metodología Montessori } \\
\text { desarrolla en el niño } \\
\text { aprendizajes de una manera } \\
\text { independiente procurando } \\
\text { que el niño se desarrolle de } \\
\text { una forma integral para que } \\
\text { pueda resolver problemas } \\
\text { sencillos de una forma } \\
\text { autónoma. }\end{array}$ \\
\hline
\end{tabular}

\section{Discusión y resultados}

Considerando que el distanciamiento social inició desde el año 2019 hasta la actualidad se tomaron como estudio 6 proyectos de pregrado de la Carrera de Educación Inicial y un proyecto de maestría en Pedagogía de la Actividad Física vinculados al proyecto macro "Estimulación multisensorial temprana basada en la metodología Montessori para niños/as de 0-5 años con o sin necesidades educativas especiales post distanciamiento social" y se realizó un análisis de la importancia y los beneficios de la estimulación multisensorial en el desarrollo infantil.

Los aportes, conceptos, teorías y resultados que fundamentan las investigaciones realizadas contribuyen para un análisis del presente trabajo.

La información de dichas investigaciones ayudó a describir importantes resultados y a sintetizar las ideas para realizar un intenso análisis sobre las variables investigadas, cada una aportó con pautas claves para lograr una mejor aplicación de estrategias que potencien las principales áreas del desarrollo infantil como lo describe el Currículo de Educación Inicial (MINEDUC, 2014). 
De los resultados evidenciados se considera que durante los años 2019 en el cual se inicia el distanciamiento social a nivel mundial el área educativa se vio totalmente afectada debido a varios factores, por un lado uno de los limitantes fue la escasa capacitación docente que tuvo que migrar de una educación presencial a una educación online la cual dificultó enormemente el trabajo con los niños para estimular las áreas de desarrollo cognitiva, motriz, social y de lenguaje en el nivel inicial, difícilmente mantener la atención del niño tras la pantalla de un computador y sumado a éste el nivel socio económico de las familias con escasos recursos.

Según Córdoba (2018), la estimulación sensorial es muy importante y favorece al desarrollo del ser humano en sus primeras etapas de crecimiento, sin embargo, con el distanciamiento social se han visto limitadas afectando al grupo más vulnerable que son los niños en su etapa infantil.

El distanciamiento social limitó el contacto de los niños, perjudicando el área afectiva ya que el ser humano por naturaleza es un ser social, el lenguaje porque el niño necesita relacionarse con otros niños para desarrollar las destrezas comunicativas, y la motricidad porque el niño manipula objetos del medio lo cual le permite adquirir nuevos aprendizajes.

A esto se suma el objetivo principal de la estimulación sensorial en la infancia que es aprovechar la capacidad de aprendizaje y adaptabilidad del cerebro en los primeros años de vida empleando diversos ejercicios, actividades o juegos que permitan brindar diferentes estímulos repetitivos, al utilizar la estimulación temprana en la primera infancia reforzamos aspectos importantes como son: intelectuales, capacidad para la lectura, cálculo matemático, aspectos físicos, sensoriales y sociales (Andalucía, 2011).

Por ende, es fundamental tener siempre en cuenta que los aprendizajes se dan a través de la estimulación sensorial pero también utilizando material que facilite la comprensión de los contenidos de manera que uno siempre los pueda relacionar con actividades que estimulen el tacto, la vista, el oído, el gusto, el olfato, la percepción, el equilibrio (Agudelo, 2017).

La estimulación sensorial en los niños de 0 a 5 años empieza desde la familia y en ciertas ocasiones esta se ve asistida por una institución educativa misma que tiene un papel fundamental en la cual la familia y educadoras en este proceso son parte determinante en la formación y el desarrollo de la personalidad de los infantes (Perdomo, 2011).

No olvidemos que en estas primeras edades el cerebro del niño está en constante desarrollo. La multiplicidad de estímulos que le lleguen hará posible la activación de millones de neuronas que le permitirán construir su propio aprendizaje e ir adentrándose de forma segura en el mundo que le rodea. 
Se deben construir espacios multisensoriales positivos, que permitan desarrollar la creatividad e inteligencia del niño desde las primeras edades considerando características individuales (Etchepareborda, 2014).

Según el currículo de Educación Inicial las destrezas que se trabajan en cada una de las edades permiten el desarrollo integral del niño en las áreas cognitivas, motrices, afectivo social y de lenguaje.

La estimulación visual. - contribuye al desarrollo de nuevos aprendizajes que le permitirá al niño desarrollar capacidades y ejecutar las funciones básicas de comprensión, atención, memoria, lenguaje, sensopercepciones, esquema corporal, lateralidad, direccionalidad, nociones temporales, motricidad fina y gruesa, aporta significativamente el proceso de interpretar imágenes y el desarrollo de habilidades en el inicio a la lectura y pre escritura en el nivel inicial.

La estimulación auditiva. - permite comprender la importancia de la correcta aplicación de la estimulación auditiva y para el desarrollo del lenguaje en los infantes. Es una experiencia positiva, alegre y divertida, no se los debe forzar a hacer ninguna actividad y al realizarla debe ser en forma de juego (Barreno \& Macías, 2015).

En esta edad es necesario conocer que, si existe una mala audición, provocará problemas en los aprendizajes relacionados al lenguaje verbal y no verbal que posteriormente dificultarán las destrezas comunicativas y las que involucran relaciones sociales en el medio en el cual se desenvuelve el niño.

La Estimulación táctil. - es un proceso muy importante dentro de la vida de cada persona, aporta de manera positiva en el aprendizaje del ser humano. Dentro de este se encuentra la sensación, que es la encargada de recibir la información del exterior a través de nuestros sentidos; también tenemos a la percepción, que cumple un papel muy importante ya que procesa la información en el cerebro para poder ser transmitida (Santander, 1991).

El tacto es el primer sentido que surge desde el nacimiento, el contacto del bebé con su madre le dará seguridad y confianza para adaptarse al contexto, por medio éste el niño discrimina temperaturas y texturas y lo ayudan a prevenir peligros que se le presentan.

Estimulación gustativa. - El primer alimento del niño es la leche materna que a través de la lactancia desarrolla el sentido del gusto y empieza a discriminar los distintos sabores, mientras sigue creciendo ira experimentando el contacto con sabores dulces, salados, amargo, ácido, agrio, sin embargo, este proceso ocurre con el paso de los meses para lo cual los diversos órganos van madurando y permitiendo que el bebé pueda familiarizarse con estos aprendizajes.

Estimulación olfativa. - Mientras va madurando el bebé también desarrolla el sentido del 
olfato, poco a poco irá discriminando los olores agradables y desagradables. El olfato al igual que los otros sentidos cuando son bien estimulados ayuda adquirir aprendizajes nuevos que le permitirán al niño la adaptación y conocimiento del entorno en el cual se desarrolla.

Estimulación vestibular. - El desarrollo motriz y precisamente la motricidad gruesa se desarrolla en el niño con la edad, la misma que le permitirá ir perfeccionando movimientos muy necesarios para la locomoción, el gateo es indispensable en este proceso porque le dará seguridad para que inicie sus primeros pasos por tal motivo los músculos de sus extremidades deben ser estimulados permitiendo al niño caminar, luego correr, saltar, galopar.

El sistema vestibular está relacionado con el equilibrio y el control espacial es el responsable de detectar desplazamientos, giros o aceleraciones para ayudar a mantener el equilibrio por esta razón la estimulación en esta edad es muy importante.

Estimulación propioceptiva. - El sistema propioceptivo es estimulado juntamente con el sistema vestibular para realizar el equilibrio y coordinación de movimientos, permite una adecuada coordinación de los movimientos, desplazamientos, capacidad motora gruesa coordinación corporal, el equilibrio, y el desarrollo de la coordinación viso motora de ojomano y pie a través de los sentidos, movimientos y posiciones para una adecuada estructuración del esquema corporal.

\section{Conclusiones}

- Según el currículo de educación inicial el área de desarrollo que deben ser estimuladas de manera integral en los niños de 0 a 5 años están distribuidas en los diferentes ámbitos de desarrollo y aprendizaje. En el subnivel 1 los ámbitos de; vinculación emocional y social, descubrimiento del medio natural y cultural, manifestación del lenguaje verbal y no verbal, exploración del cuerpo y motricidad. En el subnivel 2 los ámbitos de Identidad y autonomía, convivencia, relaciones con el medio natural y cultural, relaciones lógico/matemáticas, comprensión y expresión del lenguaje, expresión artística, expresión corporal y motricidad.

- Los sentidos son los principales responsables en la adquisición de los aprendizajes a lo largo de toda nuestra vida, de la estimulación que reciben dependerá su limitación o su efectividad favoreciendo el desarrollo integral en los 5 primeros años de vida, es notorio mediante las investigaciones realizadas las limitaciones que observadas se vieron limitados y poco atendidos durante el distanciamiento social.

- Una adecuada estimulación de los sentidos permite que el niño adquiera los 
conocimientos y aprendizajes necesarios que le permitirá resolver problemas en las distintas áreas cognitivas, afectivas, sociales, motrices y de lenguaje facilitando su adaptación dentro del contexto en el cual se desenvuelve el cuál por el distanciamiento social ha sido poco atendidos por las autoridades gubernamentales y distritales.

- Las investigaciones vinculadas al proyecto de carrera "estimulación multisensorial temprana online basada en la metodología Montessori para niños/as de 0-5 años con o sin necesidades educativas especiales post distanciamiento social" contribuyeron enormemente en la selección de estrategias que contribuyen al desarrollo de nuevos aprendizajes para potenciar destrezas como: interpretación de imágenes, el desarrollo de habilidades para la iniciación a la lectura y escritura, desarrollo de la motricidad fina y la coordinación viso manual mediante lineamientos didácticos, la aplicación de ejercicios grafo motores, desarrollo del lenguaje verbal y no verbal, destrezas y habilidades comunicativas, desarrollo socio afectivo las cuales permitirán al niño lograr su autonomía e independencia.

\section{Referencias bibliográficas}

Agudelo, P. \&. (2017). La Estimulación Sensorial en el Desarrollo Cognitivo de la Primera Infancia.

Albornoz, E., \& Guzmán, M. (2016). Desarrollo cognitivo mediante estimulación niños de 3 años. Centro Desarrollo Infantil Nuevos Horizontes. Quito, Ecuador. Universidad y Sociedad vol.8 no.4 Cienfuegos sep.-dic: http://scielo.sld.cu/scielo.php?script=sci_arttext\&pid=S221836202016000400025

Alirio, Á. A.-C. (2016). Aproximación a las pedagogías alternativas. Universidad de los Andes. (Vols. vol. 20,). Mérida, Venezuela: Educere. https://www.redalyc.org/pdf/

Andalucía. (2011). Federación de Enseñanza de CC. OO.

Ayres, A. J. (1983). Sensory integration and the child. Los Ángeles: WPS (6 ${ }^{\text {a ed.). }}$ AYRES, A.J. (1998). La integración sensorial y el niño. México: Trillas.

Baber. (2005). El Desarrollo Sensorial. España: Ernendons.

Barreno, Z. \& Macías, J. (2015). Estimulación temprana para potenciar la inteligencia motriz: importancia relación. 
http://ojs.unemi.edu.ec/index.php/cienciaunemi/article/view/205

Botella Nicolás, P. E. (2016). Aportaciones de la neurociencia cognitiva a la estimulación auditiva musical de 0 a 6 años.

Briones, R. Y. (1994). Visión Infantil. En: 8 Jornadas Andaluzas sobre la visión. Cádiz: Sociedad Andaluza de Optometría y Contactología.

Blanchard, R.J., Yang, M., Li, C.I., Gervacio, A. \& Blanchard, D.C. (2001). "Cue and context conditioning of defensive behaviors to cat odor stimuli". Neurosci Biobehav Rev, 25, 587-595

Cañete, O. (2006). Desorden del procesamiento auditivo central (DPAC). Rev. de Otorrinolaringología y cirugía de cabeza y cuello, 66. Pp. 263-273.

Carbajo, M. (2014). La sala de estimulación multisensorial. Universidad de Valladolid: http<s://dialnet.unirioja.es/descarga/articulo/5084331.pdf.

Chiquillo, H. (2015) Estimulación del lenguaje expresivo y comprensivo en la etapa inicial de los niños de 2 a 3 años del grado párvulo. file:///C:/Users/silvi/Downloads/Estimulacion_del_lenguaje_expresivo_y_compr ensivo_.pdf

Córdoba, N. (2018). Desarrollo cognitivo, sensorial, motor y psicomotor en la infancia. IC Editorial. Doi: https://elibro.net/es/ereader/uta/113433.

Etchepareborda, M. A. (2014). Estimulación multisensorial. Revista de neurología, ISSN 0210-0010, Vol. 36, N. ${ }^{\circ}$ Extra-1: https://dialnet.unirioja.es/servlet/articulo?codigo $=4658350$.

García-Albea, J. (1999). Algunas notas introductorias al estudio de la percepción. Madrid: Madrid: Alianza

Gómez, M. (2010). Aulas multisensoriales en educación especial. Madrid: Ideas propias. Madrid: Ideas propias.

Gutiérrez, D. \& Ruiz M. (2018). Impacto de la educación inicial y preescolar en el neurodesarrollo infantil. http://www.scielo.org.mx/pdf/ierediech/v9n17/24488550-ierediech-9-17-33.pdf.

Herrera, E. (2001). La estimulación y educación auditiva en el medio escolar. En La percepción auditiva un enfoque transversal (pp. 91-116). Madrid: Madrid: Editorial ICCE.

Lázaro, A. (2008). Estimulación vestibular en Educación Infantil. 
Martenot, M. (1993). Principios fundamentales de formación musical y su aplicación. Madrid: Rialp.

Martínez, J. I. (2015). Estimulación de la vía auditiva: materiales. Granada: Logopeda IES "Virgen de las Nieves".

MINEDUC. (2014) Currículo de Educación Inicial. MINEDUC

Molina, T. (2008). Diseño de un espacio sensorial para la estimulación temprana de niños con multi déficit. Revista Ingeniería Biomédica. ISSN 1909-9762, volumen 2, número 3, enero-junio págs. 40-47: http://www.scielo.org.co/pdf.

Peiró, M. d. (2017). Estudio de la discriminación auditiva en educación infantil en Valencia. España: Universidad de Valencia.

Perdomo, G. (2011). La estimulación temprana en el desarrollo creativo de los niños de la primera infancia. 29-34. https://www.redalyc.org/pdf/3606/360635574006.pdf.

Rousseau, J. (2012). Obras selectas. Argentina: Editorial Ateneo.

Rosenzweig, M. \& Leiman, A. (1992). Psicología fisiológica. McGraw Hill.

Salvador, J. (1989). La Estimulación Precoz en la Educación Especial. Barcelona, España: CEAC.

Santander, O. A. (1991). Riesgo y dificultades en la integración sensorial, aprendizaje, afectividad y conducta en estudiantes de primaria de un colegio oficial. Fundación Universitaria de Popayán.

Takahashi, L. N. (2005). El olor de peligro. "The smell of danger". Takahashi, L.K., Nakashima, B.R., Hong, H., Watanabe, K. (2005). "The smell of.

Tamayo, R. (2000). Estimulación Temprana en el niño pequeño. http://www.neurorehabilitacion.com/estimulacion_temprana.htm\#

Téllez, L. (2003). Introducción a la Estimulación Temprana, pág. 5-10.

Tinajero. A. \& Mustard, J. (2011). Reporte presentado a la BernardVan Leer. Foundation, documento en proceso de publicación.

Vermetten, E. \& Bremner, J. D. (2003). "Olfaction as a traumatic reminder in posttraumatic stress disorder: case reports and review". J Clin Psychiatry, 64, 202207

Warnok, M. (2014). La estimulación en conjunto con el sistema. 


\section{DDigital}

ISSN: 2600-5859

Vol. 6 No. 1.4. pp. 141 - 162, marzo 2023

www.concienciadigital.org

http://www.iesalc.unesco.org.

Woolfolk A (1986). Psicología de la educación para profesores, Narcea.

\section{\Ciencia}


El artículo que se publica es de exclusiva responsabilidad de los autores y no necesariamente reflejan el pensamiento de la Revista Conciencia Digital.

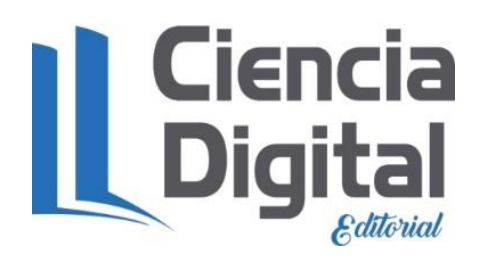

El artículo queda en propiedad de la revista y, por tanto, su publicación parcial y/o total en otro medio tiene que ser autorizado por el director de la Revista Conciencia Digital.
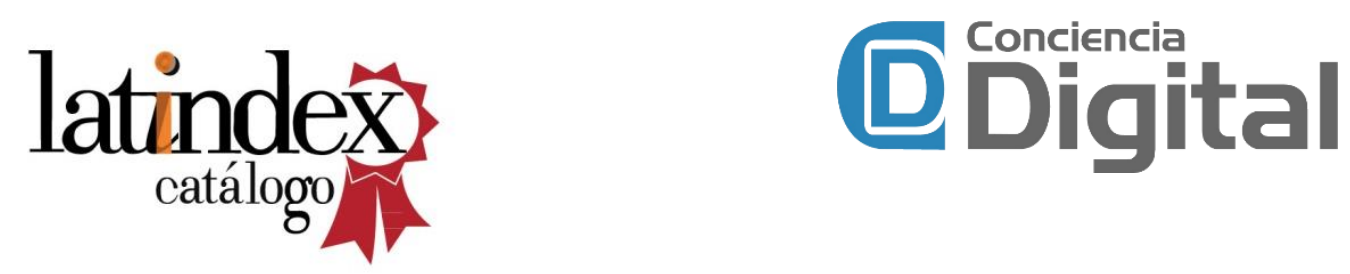

Indexaciones

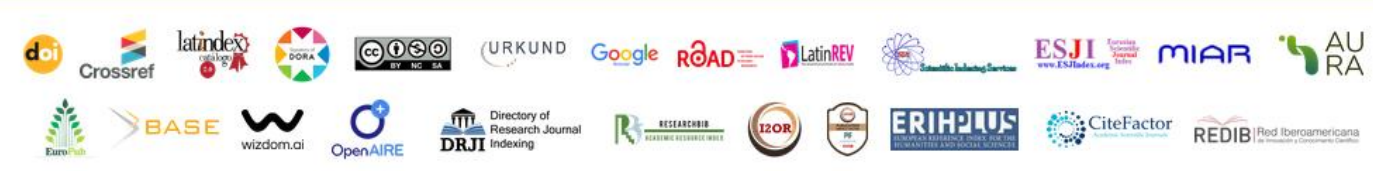

